\title{
AP1000 Shield Building Dynamic Response for Different Water Levels of PCCWST Subjected to Seismic Loading considering FSI
}

\author{
Daogang Lu, Yu Liu, and Xiaojia Zeng \\ Beijing Key Laboratory of Passive Nuclear Safety Technology, North China Electric Power University, Beijing 102206, China \\ Correspondence should be addressed to Yu Liu; appleplanter@gmail.com
}

Received 8 October 2014; Accepted 12 January 2015

Academic Editor: Alejandro Clausse

Copyright (C) 2015 Daogang Lu et al. This is an open access article distributed under the Creative Commons Attribution License, which permits unrestricted use, distribution, and reproduction in any medium, provided the original work is properly cited.

\begin{abstract}
Huge water storage tank on the top of many buildings may affect the safety of the structure caused by fluid-structure interaction (FSI) under the earthquake. AP1000 passive containment cooling system water storage tank (PCCWST) placed at the top of shield building is a key component to ensure the safety of nuclear facilities. Under seismic loading, water will impact the wall of PCCWST, which may pose a threat to the integrity of the shield building. In the present study, an FE model of AP1000 shield building is built for the modal and transient seismic analysis considering the FSI. Six different water levels in PCCWST were discussed by comparing the modal frequency, seismic acceleration response, and von Mises stress distribution. The results show the maximum von Mises stress emerges at the joint of shield building roof and water around the air inlet. However, the maximum von Mises stress is below the yield strength of reinforced concrete. The results may provide a reference for design of the AP1000 and CAP1400 in the future.
\end{abstract}

\section{Introduction}

The passive containment cooling system water storage tank is key equipment which should remain operational after earthquakes to ensure the passive safety of the AP1000. As the quality of PCCWST is approximately 3000 ton. The presence of water in water tank might have an important influence on the dynamic behavior of the shield building and can affect the safety of the shield building under seismic loading from an earthquake with long-period component [1].

As for conventional assessment of nuclear equipment, the response spectrum focuses on the short-period seismic component because there is little equipment with fundamental period above $5 \mathrm{~s}$ [2]. However, for PCCWST, the sloshing frequency is beyond that value. Therefore, it is necessary to investigate the dynamic behavior of the elevated water tank under long-period earthquake considering FSI phenomenon especially the water sloshing.

Fluid-structure interaction of elevated tank has been studied numerically and experimentally by many researchers. Livaoğlu and Doğangün [3] presented a review of simplified seismic design procedures for elevated tanks and the applicability of general-purpose structural analyses programs to fluid-structure-soil interaction problems for these kinds of tanks. It turned out that the distributed added mass with the sloshing mass is more appropriate than the lumped mass assumptions for finite element modelling. Moslemi et al. [4] adopted the finite element (FE) technique to investigate the seismic response of liquid filled tanks considering the effect of tank wall flexibility and sloshing of the water free surface. El Damatty conducted a small scaled liquid filled conical tank model to study the elevated water tank. He found a very good agreement between the experiment and analytical model for the fundamental sloshing frequency. Masoudi et al. [5] discuss the failure mechanism of elevated concrete tanks with shaft and frame staging (supporting system) along with seismic behavior of these construction types.

The AP1000 shield building has also been studied by researchers recently. Lee et al. [6] and [1] investigated the influence of elevation and shapes of air inlets on AP1000 shield building by FEM. The simulation result indicated that an optimal parametric design for air intake must be implemented around the middle of the shield building, with 16 circular or oval shaped air intake.

The PCCWST is the water source of cooling water which guarantees the 72 hours safety without operator actions. However, with the water draining to cool down the inner steel containment, the change of huge water volume may 
influence the dynamic behavior of shield building under seismic loading. In current study, a finite element model of AP1000 shield building was established and the different water levels were discussed for both modal and transient analysis. The FEM results may also provide a reference for design of the AP1000 and CAP1400 in the future.

\section{Theory of Fluid-Structure Interaction}

For a structural system, the governing equation derived from finite element formulation can be obtained as follows:

$$
M \ddot{u}+C \dot{u}+K u=F,
$$

where $M, C$, and $K$ are mass, damping, and stiffness matrix for structure and $u$ is the displacement vector. $F$ is the total force applied by other systems. However, for fluid-structure interaction problem, the FSI can be expressed by coupling the governing equation of the structure and fluid at the interface. The interface force caused by the fluid pressure at the interface is transferred to the structure. So the $F$ of equation can be extended to

$$
F=F^{\prime}+F^{p}
$$

where $F^{p}$ is the integration of fluid pressure on the fluidstructure interface and $F^{\prime}$ is the external force excluding $F^{p}$. The fluid pressure field can be derived from the following equation assuming the fluid as incompressible and inviscid:

$$
\frac{1}{c} \frac{\partial^{2} P}{\partial t^{2}}-\nabla^{2} P=0
$$

where $c$ is the fluid sound speed and $t$ is the time. The detailed formula deduction can refer to the work by Choi et al. [7]. The final matrix equation involves nonsymmetric and stiffness matrix. The eigenvalues of the coupled problem can be obtained with unsymmetrical algorithm for modal analysis by ANSYS.

For FEM transient analysis, the Newmark algorithm is an effective way of solving the structural response. In Newmark's algorithm, Rayleigh damping is adopted for defining the damping denoted as

$$
\begin{aligned}
& C=\alpha M+\beta K, \\
& \alpha=\frac{2 \xi \omega_{1} \omega_{2}}{\omega_{1}+\omega_{2}}, \\
& \beta=\frac{2 \xi}{\omega_{1}+\omega_{2}},
\end{aligned}
$$

where $\alpha$ and $\beta$ are the mass and stiffness proportional Rayleigh damping coefficient, respectively. The $\xi, \omega_{1}$, and $\omega_{2}$ are damping ratio, the first and second undamped natural frequency of the structure. According to the AP1000 DCD [8], the damping ratio $7 \%$ is adopted. In materials science and engineering the von Mises yield criterion is used to predict yielding of materials. A material is said to start yielding when its von Mises stress reaches a critical value known as the yield strength. In this paper, the yield strength of reinforced concrete $27.6 \mathrm{MPa}$ is used according to the AP1000 DCD.

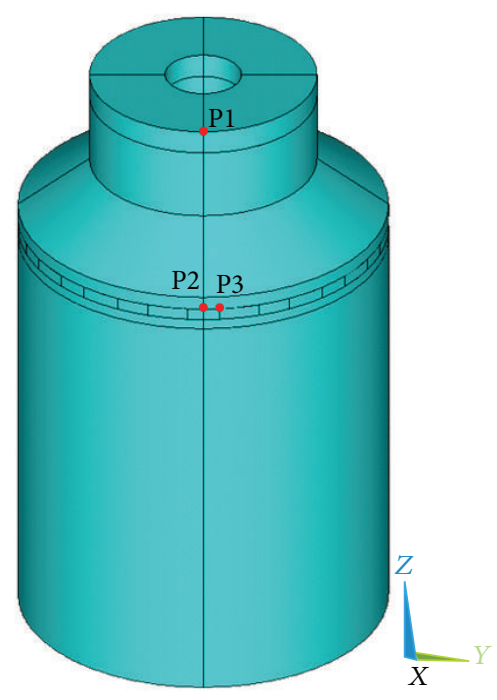

FIGURE 1: The geometry of shield building.

TABle 1: The geometry of shield building.

\begin{tabular}{lccc}
\hline Geometry & \multicolumn{3}{c}{ Dimension $/(\mathrm{m})$} \\
& Height & Diameter & Thickness \\
\hline Shield building & 71 & 44.2 & 0.9 \\
PCCWST & $5.8 / 11.5$ & $9.0 / 27.1$ & 0.5 \\
Water & 8.6 & $9.0 / 27.1$ & - \\
\hline
\end{tabular}

TABLE 2: The material properties.

\begin{tabular}{lccc}
\hline Material & $\begin{array}{c}\text { Density/ } \\
\left(\mathrm{kg} / \mathrm{m}^{3}\right)\end{array}$ & $\begin{array}{c}\text { Elastic module/ } \\
(\mathrm{GPa})\end{array}$ & Poisson ratio \\
\hline $\begin{array}{l}\text { Uniform reinforced } \\
\text { Concrete }\end{array}$ & 2300 & 33.5 & 0.2 \\
Water & 1000 & - & - \\
\hline
\end{tabular}

\section{Structural Assessment of AP1000 PCCWST by FEM Model}

3.1. AP1000 PCS. The main part of the structure for shield building includes shield building wall with 16 rectangular cooling air intakes, the shield building roof, PCCWST, and water shown as Figure 1. The uniform reinforced concrete model is adopted to simulate shield building. The material properties and geometric conditions are shown in Tables 1 and 2. In this paper, six different water levels (Table 3) corresponding to the $100 \%, 80 \%, 60 \%, 40 \%, 20 \%$, and $0 \%$ of operational water volume are analyzed to figure out the structure assessment of water level decreasing owing to the water draining in accident scenario. Both modal analysis and transient analysis are carried out for six different water levels.

3.2. FEM Model. The pressure-based fluid element Fluid 30 is used to model the water in PCCWST, which is suitable for fluid-structure interaction analysis $[3,4,9,10]$. In order to reduce the calculation cost, the shield building wall, roof, and 
TABLE 3: The modal analysis results of six different water levels.

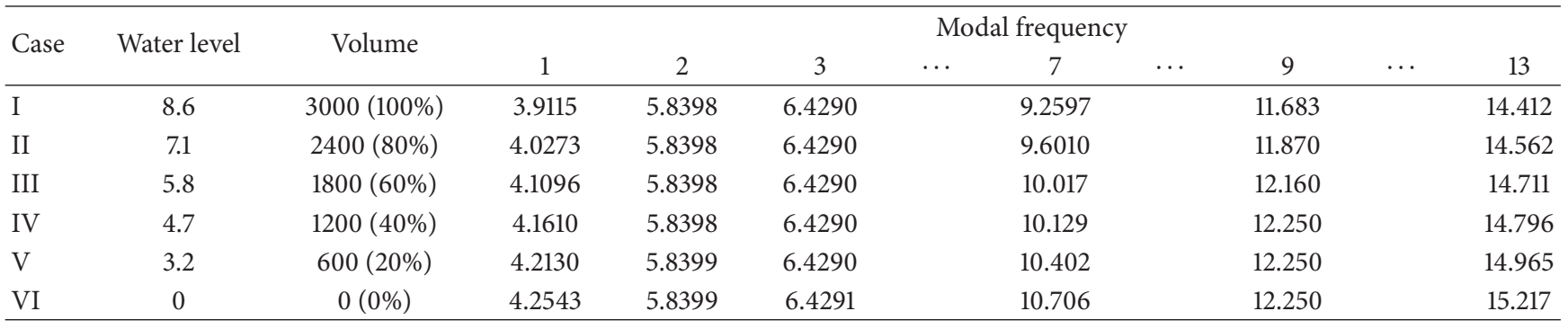

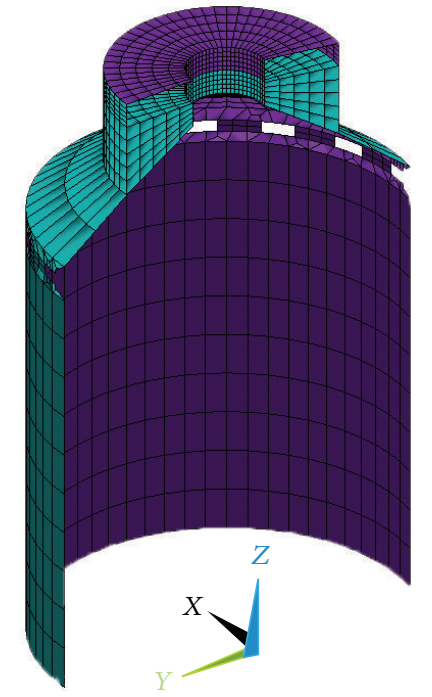

FIGURE 2: The shield building mesh viewed by partial section.

PCCWST are modeled by shell element Shell63 rather than solid element. The mesh of shield building is illustrated in Figure 2 with a partial section view.

For boundary condition, atmospheric pressure is applied to the free water surface. The fluid-structure coupling pressure boundary condition is defined at the PCCWST wall and bottom. The contact nodes of water and structure are merged to maintain identical displacement which assure the water and the structure will not separate or penetrate.

For modal analysis, the boundary condition for the analysis is that all the nodes of the shell elements at the foundation level are fixed; that is, the displacements, translational or rotational, were set to zero. Unsymmetrical algorithm, which is specifically useful for fluid-structure modal problem, is adopted for modal analysis by ANSYS. For transient analysis, the north-south direction time acceleration history of El Centro wave $(0.35 \mathrm{~g})$ is applied to the shield building. Newmark's numerical method was used for the structural response of shield building in the time domain analysis. Rayleigh damping was also used to simulate the structural damping. The damping coefficient was assumed as $7 \%$.

The size of mesh is a key factor for the accuracy of FE results. While pursuing higher accuracy, the computational cost has to be well evaluated. In this study, 3 sizes of element are adopted: $1.0,1.5$, and $2.0 \mathrm{~m}$ with error of $0.209 \%$ and $0.18 \%$ subjecting to the maximum seismic acceleration response of shield building top (Point 1 in Figure 1). Therefore the element size $1.0 \mathrm{~m}$ is chosen for the final computation with 32224 nodes and 3320 elements.

\section{Results and Discussion}

4.1. Modal Analysis. This paper focused on the influence on dynamic response of shield building of different water levels in PCCWST considering the FSI phenomenon. Six cases of water levels shown in Figure 3 corresponding to $100 \%, 80 \%, 60 \%, 40 \%, 20 \%$, and $0 \%$ of operational water level were selected to be analyzed. In the modal analysis, there were totally 40 modal shapes that have been extracted. According to characteristics of cylindrical building modal shape, some significant modal shapes and corresponding modal frequencies were listed in Table 3 and Figure 4.

As shown in Figure 4, in which the color represented the $X$ direction displacement, the first modal frequency is the bending mode of the shield building; moreover, the following two modes are the buckling of the shield building. The 7 th modal shape is the local deformation of shield building roof, while the 9th modal is the bending of PCCWST. The 13th modal shape is similar to the 7 th modal shape, however, with a considerable bending of shield building.

According to Table 3, the first modal frequencies increase slightly from Case I to Case VI. This can be explained sketchily by the following equation:

$$
f=\frac{1}{2 \pi} \sqrt{\frac{K}{M}} .
$$

We assume the whole shield building as a single degree of freedom cantilever beam with "solid water" attached to the top. The floating water can hardly change the structure stiffness $K$; however, the decreasing water will reduce the total mass of structure $M$, which leads to the increasing of fundamental frequency $f$. The frequency changes are so small that the mass difference of six cases is relatively small compared with the total mass of shield building. Another finding is that the 2 nd and 3 rd modal frequencies are almost the same for different water level cases. This is because the higher modes are the local deformation of shield building, which can be proved that the displacement of PCCWST is almost zero with a uniform color distribution in its modal shape. For 7th, 9th, and 13th modal frequencies increase from Case I to Case VI with the similar trend with first 


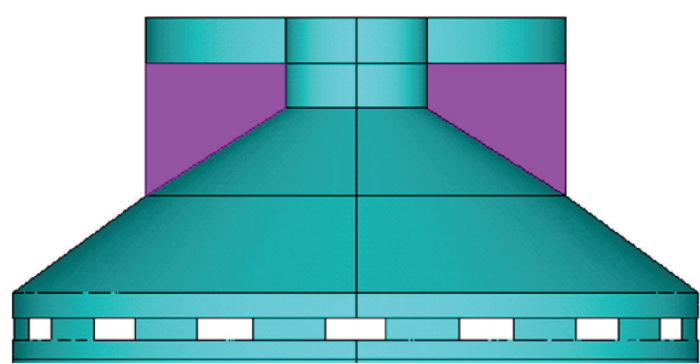

(a)

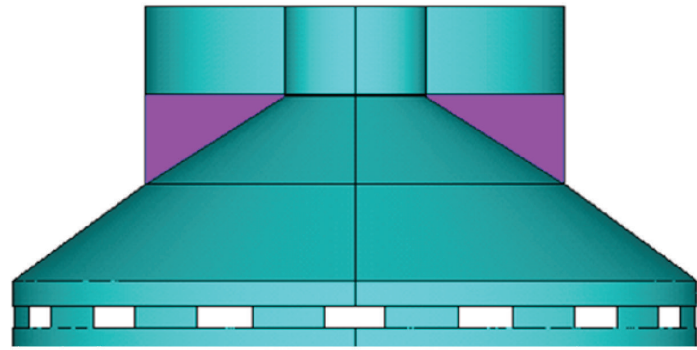

(c)

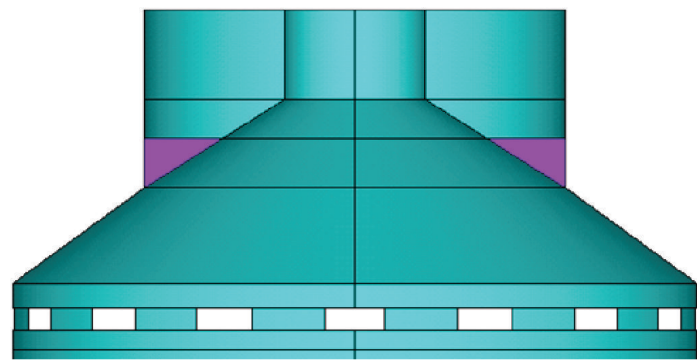

(e)

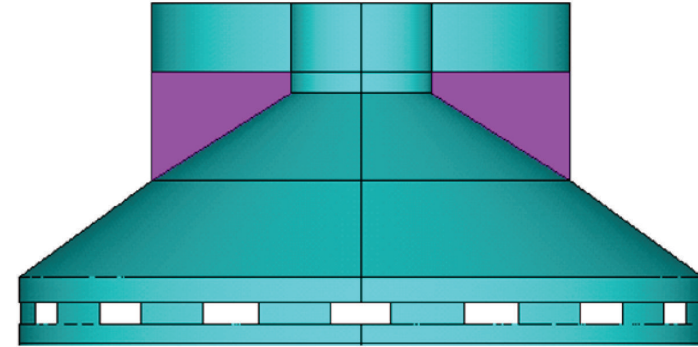

(b)

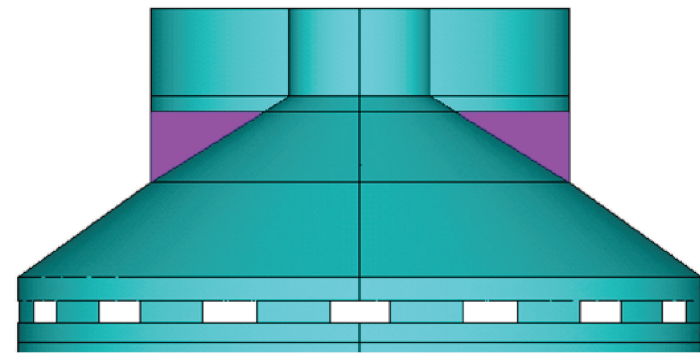

(d)

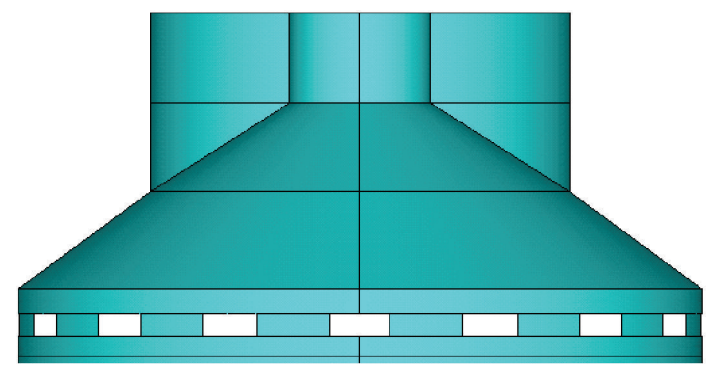

(f)

Figure 3: Water levels ranged from Case I to Case VI.

modal shape. This means the mass of water influences the local structures consisted of PCCWST and shield building roof.

4.2. Transient Analysis. This paper studied the influence of various water levels on the safety and integrity of shield building subjecting to seismic loading. El Centro acceleration time histories with acceleration amplitude $0.35 \mathrm{~g}$ were applied to the shield building. Figure 5 shows the north-south direction of El Centro wave which was used as the ground acceleration time history in this paper.

Figure 6(a) illustrated Case I distribution of von Mises stress at the time $2.58 \mathrm{~s}$, the time when maximum stress occurs during the whole time history. The maximum von Mises stress for six cases was 9.21, 9.13, 8.04, 7.01, 6.80, and 6.28 $\mathrm{MPa}$, respectively, all occurring at the joint of shield building roof and inside wall. The maximum von Mises stress for all six cases is below the 27.6 MPa yield strength given by AP1000 DCD. However, due to the effect of air inlet, the maximum values happened around the air inlet corner rather than on the symmetry plane of shield building, which is the results of stress concentration seen from Figure 6(a). Although, along the whole time history, the overall maximum stress happened at this special location, at certain time, maximum stress can also take place at the bottom of shield building outside wall or at the bottom of PCCWST. Figures 6(b) and 6(c) are the typical states of stress distribution illustrating these states.

The acceleration response is a very significant index reflecting the structure motion. In this study, Point 1 at the top of the building was chosen to reveal the seismic response because the response of this point is relatively large. Time history curve is an effective way of showing the transient response; however, the overlapping curves are hard to distinguish from each other when comparing different curves. In this paper, the upper and lower envelopes of time history curve are used to show the seismic response of the structure because we focus more on the maximum value. The envelopes of acceleration time history at Point 1 for different cases are illustrated in Figure 7. The acceleration responses are similar for all six cases especially at the 2.5 and 10 seconds with extremely high peaks corresponding to the seismic loading. Obviously, in Figure 7, the maximum and average acceleration response of case I is the largest among six cases. This means the acceleration response of shield building top is decreasing with the water level reducing. However, 


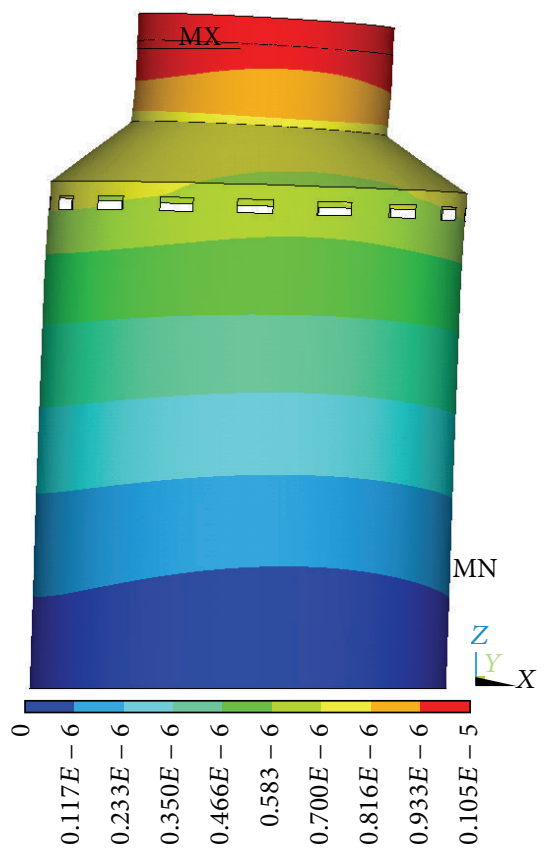

(a) The fundamental mode shape

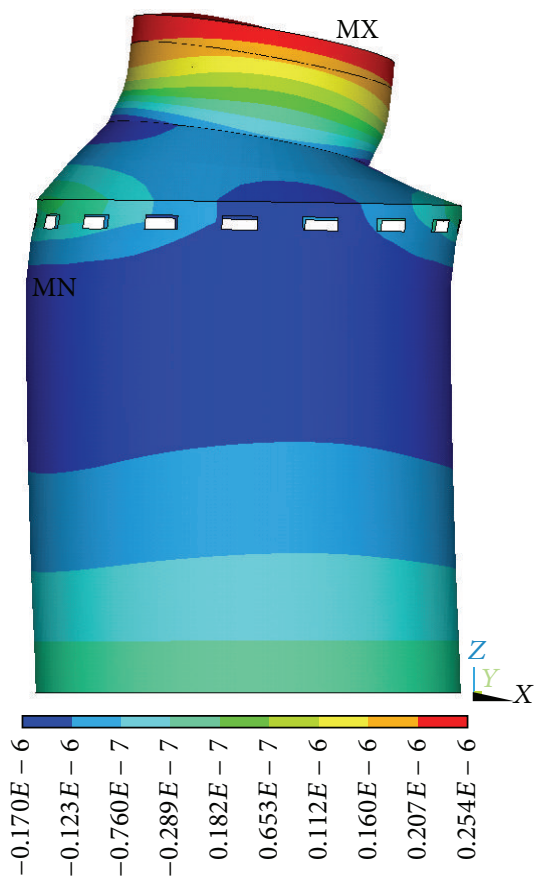

(d) The 7th mode shape

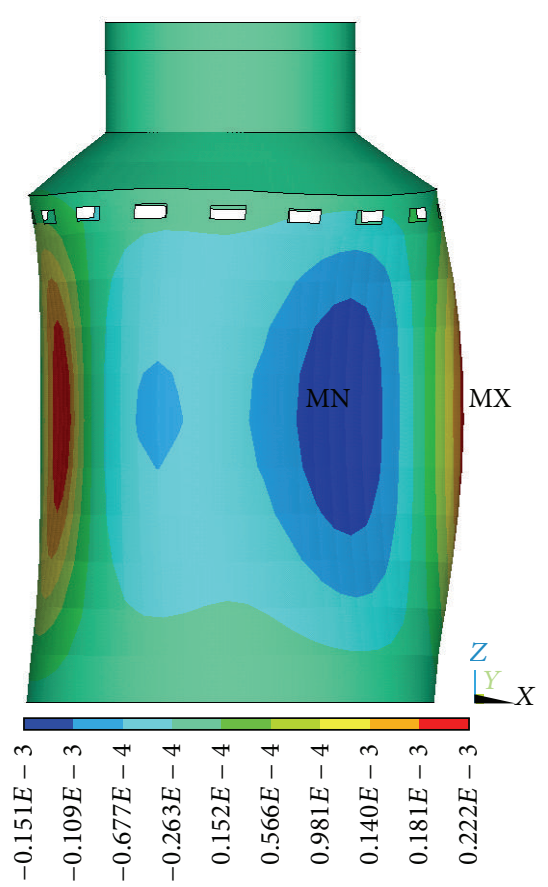

(b) The 2nd mode shape

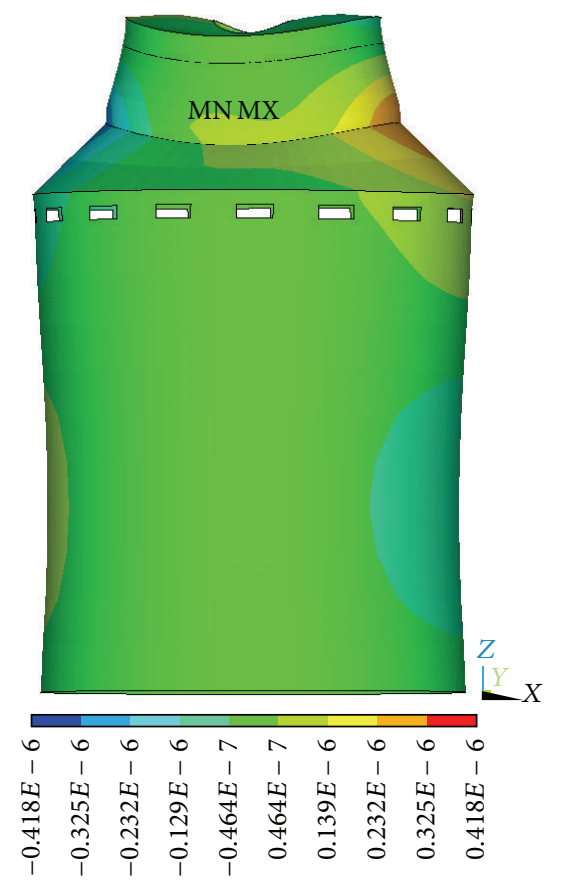

(e) The 9th mode shape

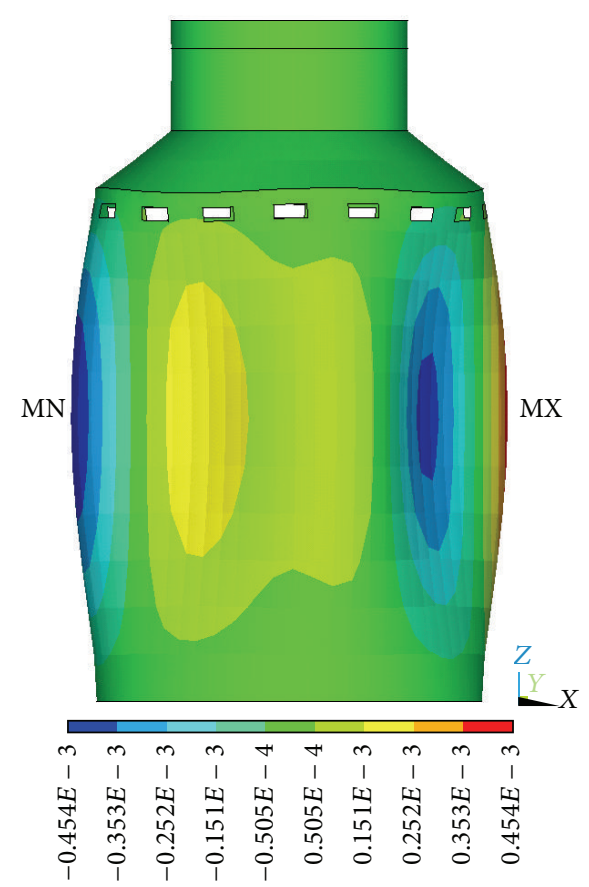

(c) The 3rd mode shape

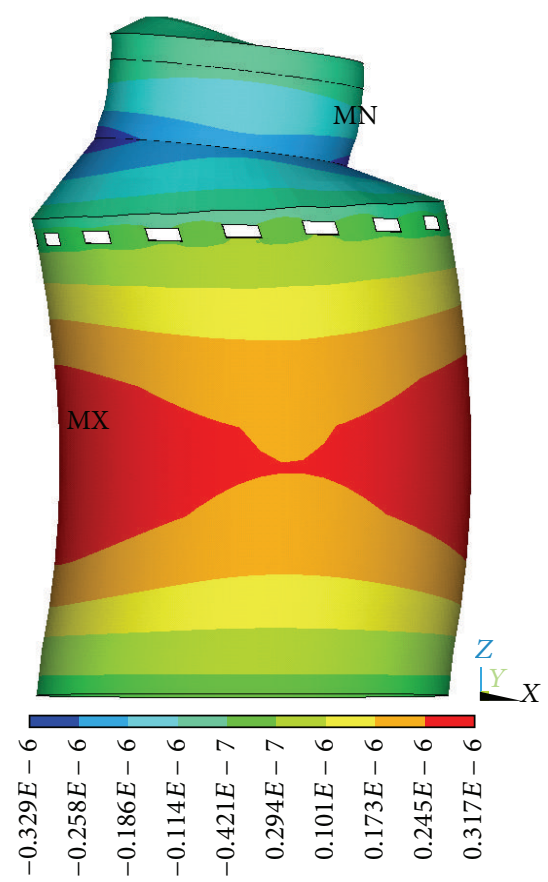

(f) The 13th mode shape

FIgURE 4: The mode shape of shield building.

response of Case VI has more considerable amplitude at the 15 seconds. This is probably caused by the deformation of the shield building roof corresponding to the higher modal shape such as 7 th, 9th, and 13th. The corresponding displacement responses of Point 1 are illustrated in Figure 8. A similar response as the acceleration curve was obtained with the maximum displacement of 2.56, 2.46, 2.39, 2.26, 2.16, and $2.06 \mathrm{~cm}$ for six cases, respectively.

The maximum von Mises stress emerges at the joint of shield building wall and roof around the air intake. Consequently, von Mises stress of the two selected points (Points 2 and 3 in Figure 1) around air intake is plotted in 


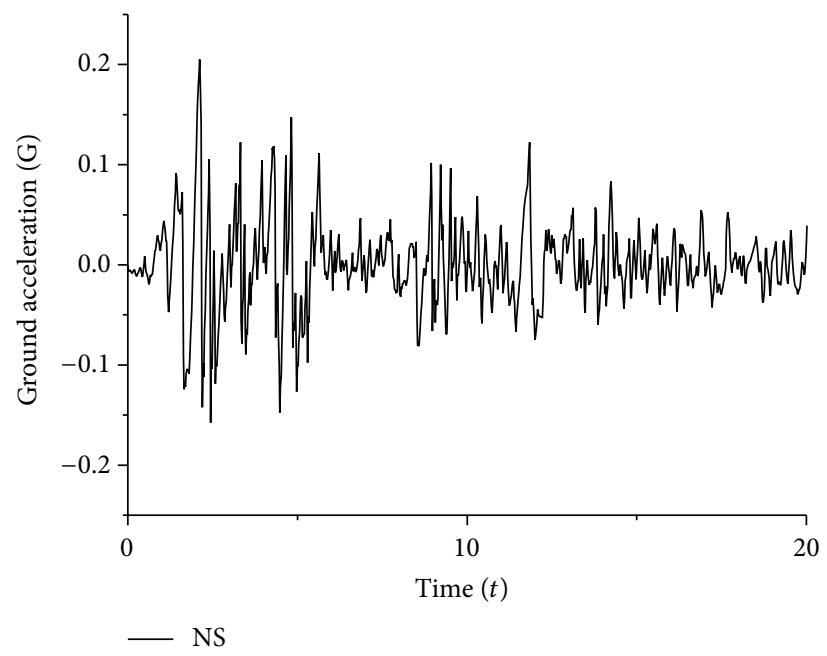

FIgURE 5: The El Centro wave time history with $0.35 \mathrm{~g}$.

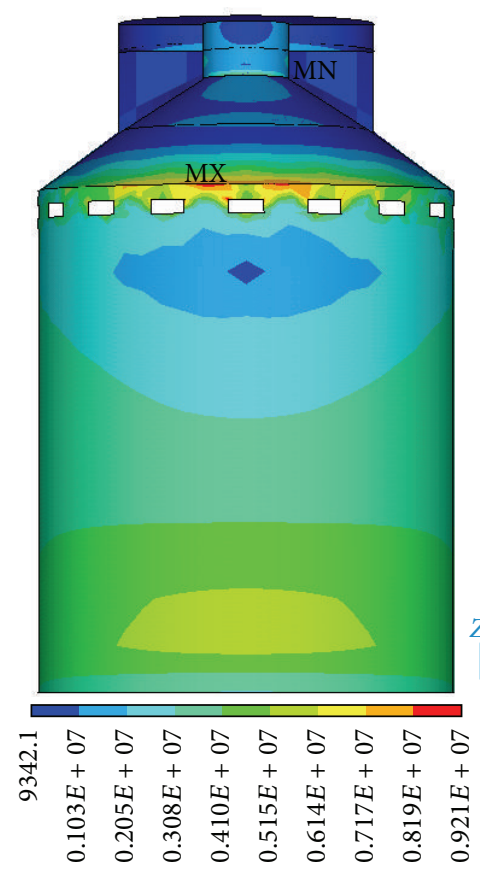

(a) 2.58 seconds

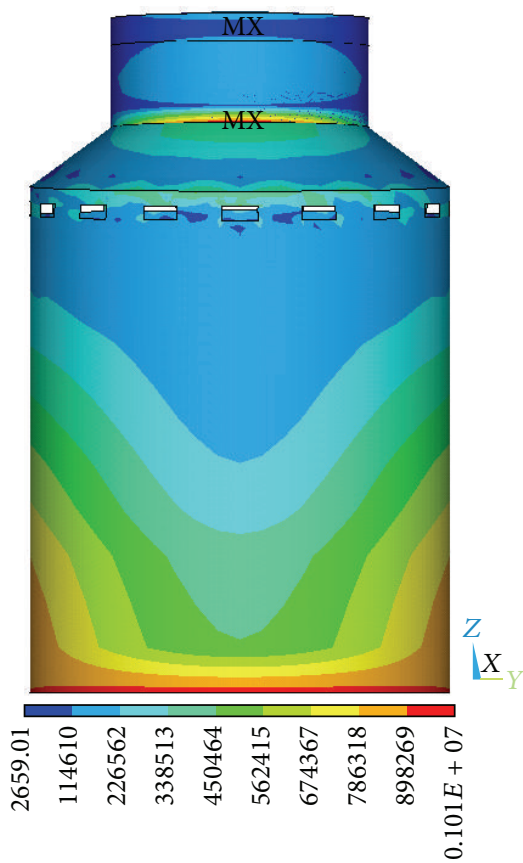

(b) 2.64 seconds

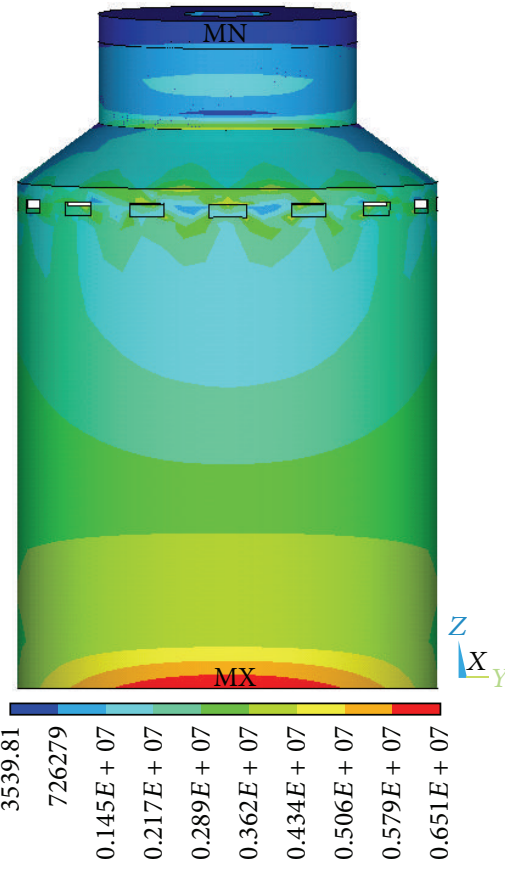

(c) 2.6 seconds

FIgURE 6: The von Mises stress distribution of shield building of Case I.

TABLE 4: The maximum transient data and the relative difference compared with Case I.

\begin{tabular}{lcccc}
\hline Response & Displacement $(\mathrm{cm})$ & Acceleration $\left(\mathrm{m} / \mathrm{s}^{2}\right)$ & \multicolumn{2}{c}{ von Mises stress $(\mathrm{MPa})$} \\
\hline Position & Point 1 & Point 1 & Point 2 & Point 3 \\
Case I & $2.563(0 \%)$ & $13.410(0 \%)$ & $6.507(0 \%)$ & $8.563(0 \%)$ \\
Case II & $2.469(3.66 \%)$ & $12.580(6.18 \%)$ & $6.270(3.64 \%)$ & $8.265(3.48 \%)$ \\
Case III & $2.391(6.71 \%)$ & $11.599(13.51 \%)$ & $5.554(14.60 \%)$ & $7.330(14.40 \%)$ \\
Case IV & $2.269(11.47 \%)$ & $10.777(19.63 \%)$ & $5.096(21.68 \%)$ & $4.946(42.24 \%)$ \\
Case V & $2.163(15.61 \%)$ & $9.916(26.05 \%)$ & $4.801(26.21 \%)$ & $4.469(47.81 \%)$ \\
Case VI & $2.060(19.63 \%)$ & $9.194(31.42 \%)$ & $4.399(32.40 \%)$ & $4.001(53.28 \%)$ \\
\hline
\end{tabular}




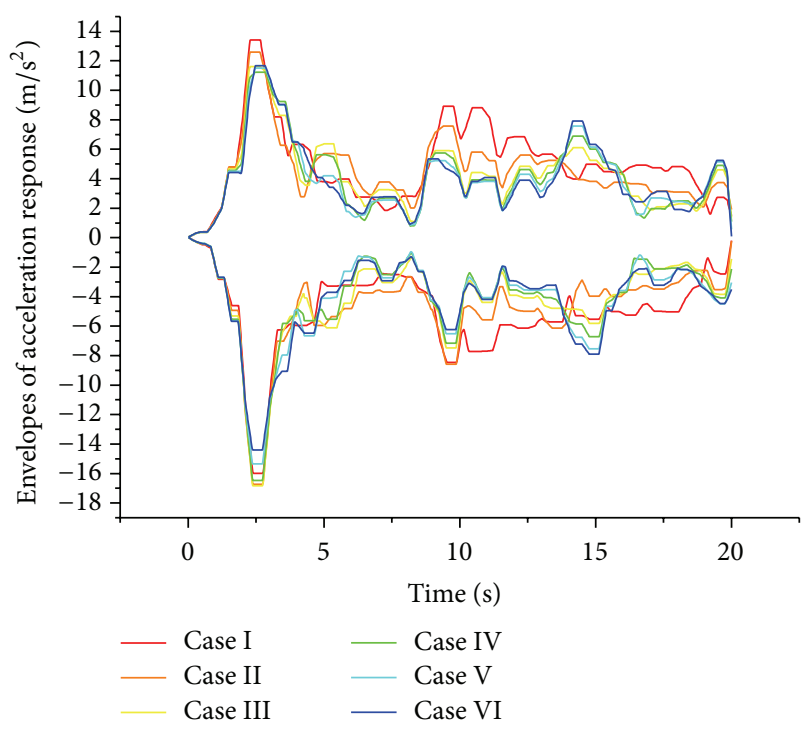

Figure 7: The envelopes of acceleration time history at Point 1.

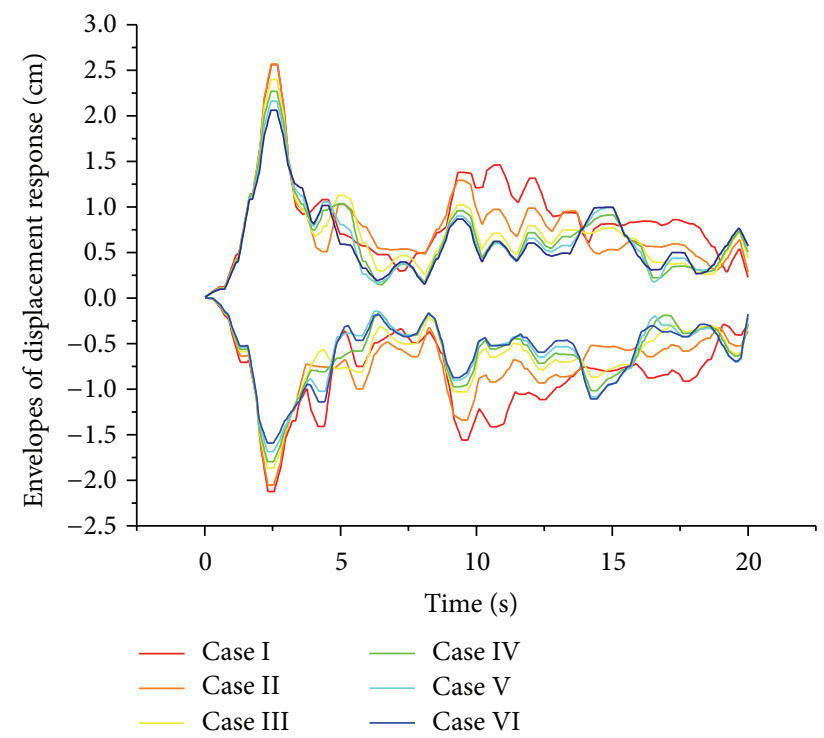

FIgURE 8: The envelopes of displacement time history at Point 1.

Figures 9 and 10. The two figures show similar curves with different amplitudes. Table 4 concludes the maximum value of seismic response to different water levels in PCCWST and the relative difference compared with Case I. It can be seen that nearly all response values decreased with the reduced water volume. The decreased responses are basically following a linear pattern with the decreased water volume especially for the displacement response, acceleration response, and stress response at Point 2. The results show that PCCWST with water draining up is much safer than that with an operational water level. The change is relatively large with a displacement reduction $19.6 \%$, an acceleration reduction $31.4 \%$, and a stress reduction $32 \%$ at Point 2 . However, the reduction of stress response at Point 3 is not linear, which may be caused by the stress concentration.

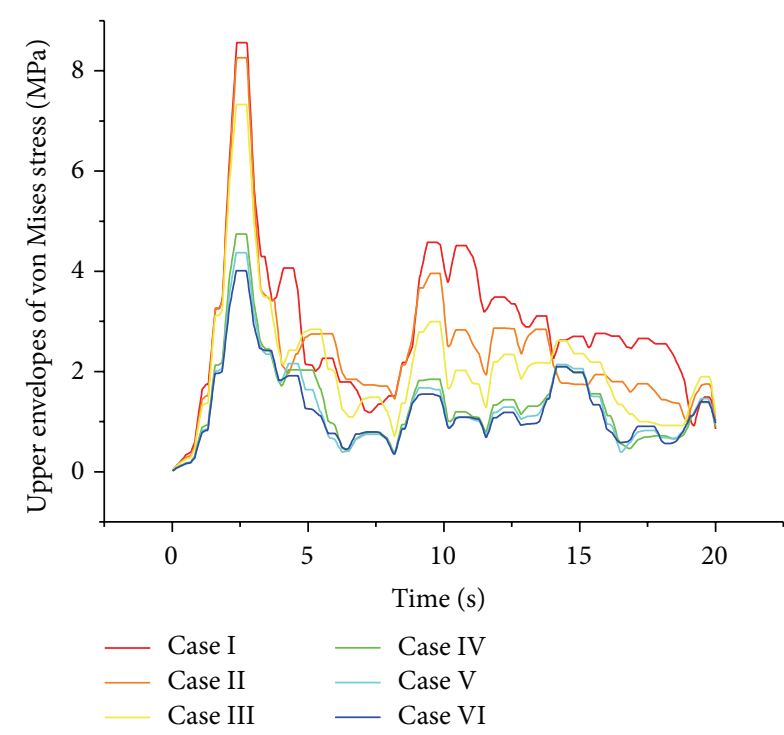

FIgURE 9: The upper envelopes of von Mises stress time history at Point 3.

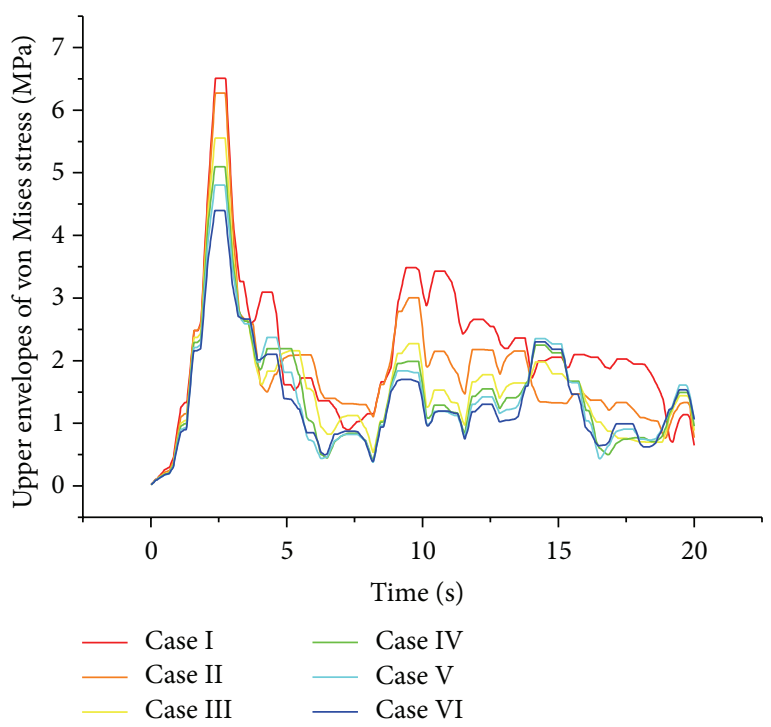

FIgURE 10: The upper envelopes of von Mises stress time history at Point 2.

\section{Conclusions}

The structural modal and seismic response of shield building have been investigated considering fluid-structure interaction for different water levels. The modal results show the reduction of water level will increase the fundamental frequency of shield building as well as the modal frequency of shape modal corresponding to the local deformation of shield building roof and PCCWST. For higher order of modal, the modal frequency is hardly influenced by the water level. However, the influence of water level is relatively small because the water mass only takes up a very small proportion of shield building. For seismic response of shield building, the maximum acceleration of shield building top for Case VI 
is about $31 \%$ less than that of Case I. The maximum displacement of the same position for Case VI is about $19.63 \%$ less than that of Case I. The von Mises stress at different point around the air intake for Case VI is about 32\% and $53 \%$ less than that of Case I. All responses are inclining with the reduction of water volume, although the decreased stress responses at air inlet corner are not following a linear pattern with the decreased water volume. The results indicated the decreasing water level will reduce the structure response, which means even when water in the PCCWST is draining to empty, the shield building can still stand the earthquake with enough margin.

\section{Conflict of Interests}

The authors declare that there is no conflict of interests regarding the publication of this paper.

\section{Acknowledgment}

The project was sponsored by National Science and Technology Major Project of the Ministry of Science and Technology of China (2012ZX06004-012-004).

\section{References}

[1] C. Zhao, J. Chen, and Q. Xu, "Dynamic analysis of AP1000 shield building for various elevations and shapes of air intakes considering FSI effects subjected to seismic loading," Progress in Nuclear Energy, vol. 74, pp. 44-52, 2014.

[2] M. Jolie, M. M. Hassan, and A. A. El Damatty, "Assessment of current design procedures for conical tanks under seismic loading," Canadian Journal of Civil Engineering, vol. 40, no. 12, pp. 1151-1163, 2013.

[3] R. Livaoğlu and A. Doğangün, "Simplified seismic analysis procedures for elevated tanks considering fluid-structure-soil interaction," Journal of Fluids and Structures, vol. 22, no. 3, pp. 421-439, 2006.

[4] M. Moslemi, M. R. Kianoush, and W. Pogorzelski, "Seismic response of liquid-filled elevated tanks," Engineering Structures, vol. 33, no. 6, pp. 2074-2084, 2011.

[5] M. Masoudi, S. Eshghi, and M. Ghafory-Ashtiany, "Evaluation of response modification factor (R) of elevated concrete tanks," Engineering Structures, vol. 39, pp. 199-209, 2012.

[6] D.-S. Lee, M.-L. Liu, T.-C. Hung, C.-H. Tsai, and Y.-T. Chen, "Optimal structural analysis with associated passive heat removal for AP1000 shield building," Applied Thermal Engineering, vol. 50, no. 1, pp. 207-216, 2013.

[7] Y. Choi, S. Lim, B.-H. Ko et al., "Dynamic characteristics identification of reactor internals in SMART considering fluidstructure interaction," Nuclear Engineering and Design, vol. 255, pp. 202-211, 2013.

[8] Westinghouse, The AP1000 European DCD, UK AP1000 Safety, Security, and Environmental Report, p. 51-53.

[9] N. Hosseinzadeh, H. Kazem, M. Ghahremannejad, E. Ahmadi, and N. Kazem, "Comparison of API650-2008 provisions with FEM analyses for seismic assessment of existing steel oil storage tanks," Journal of Loss Prevention in the Process Industries, vol. 26, no. 4, pp. 666-675, 2013.
[10] H. Sezen, R. Livaoglu, and A. Dogangun, "Dynamic analysis and seismic performance evaluation of above-ground liquidcontaining tanks," Engineering Structures, vol. 30, no. 3, pp. 794803, 2008. 


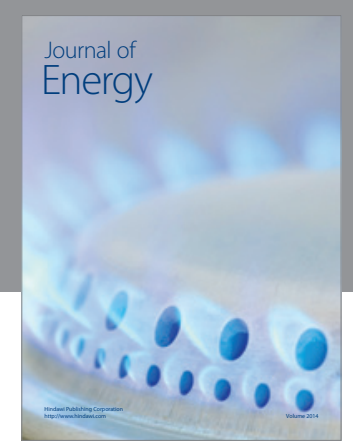

Journal of

Industrial Engineering
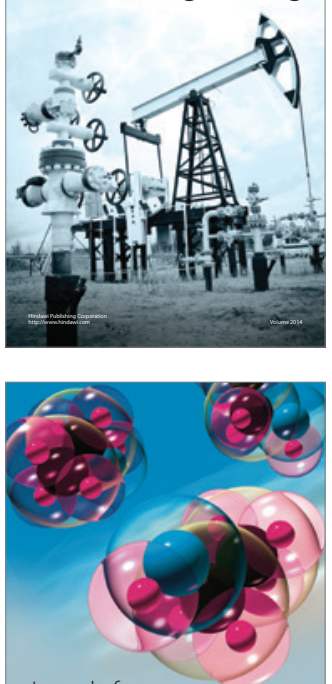

Fuels
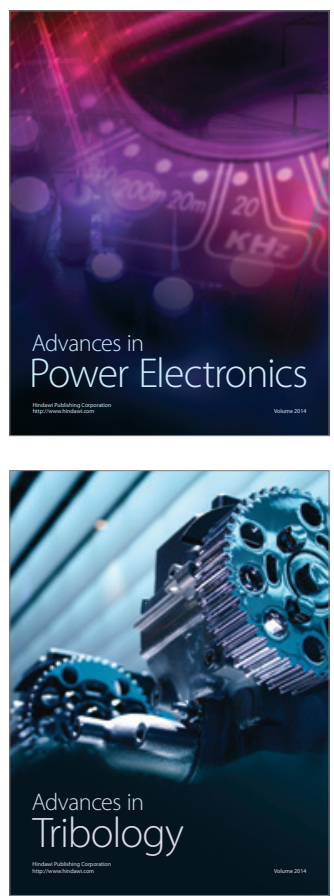

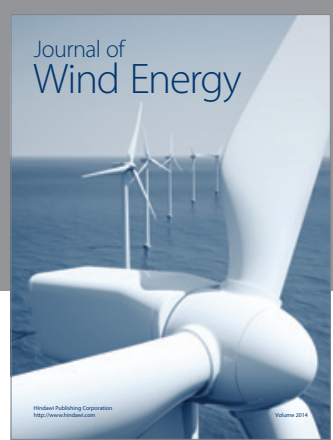

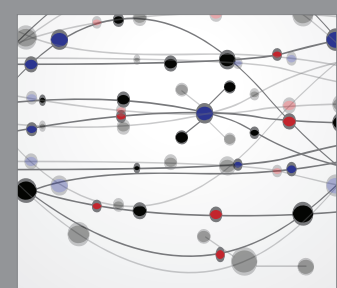

The Scientific World Journal

Submit your manuscripts at http://www.hindawi.com

Journal of

Structures
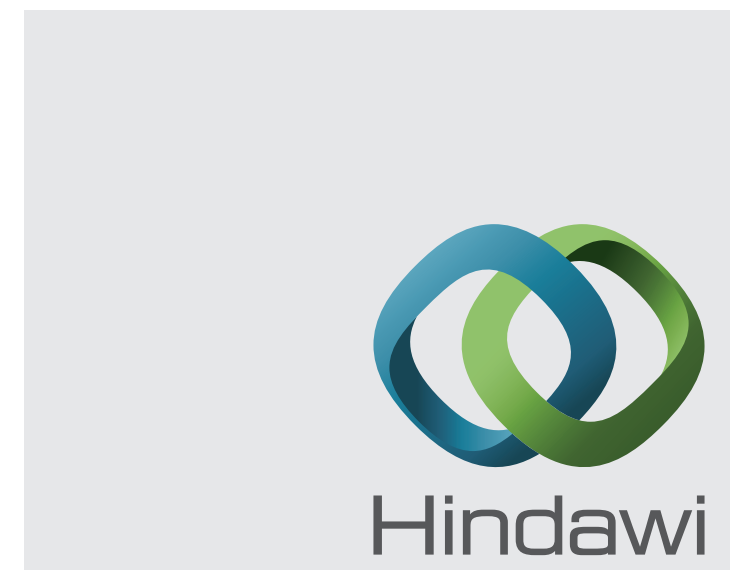

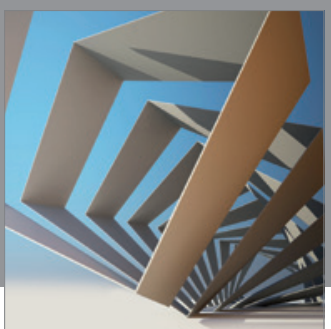

Rotating

Machinery
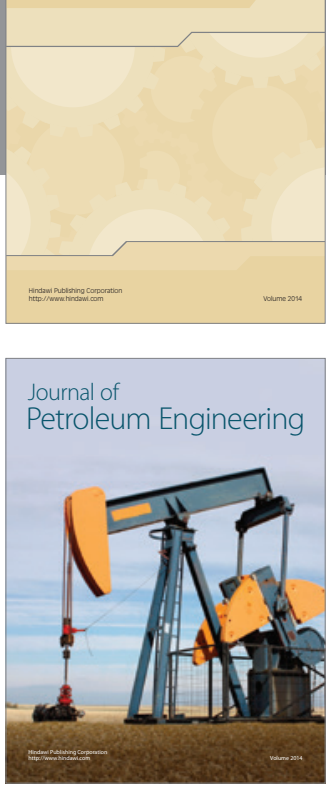

Journal of

Solar Energy
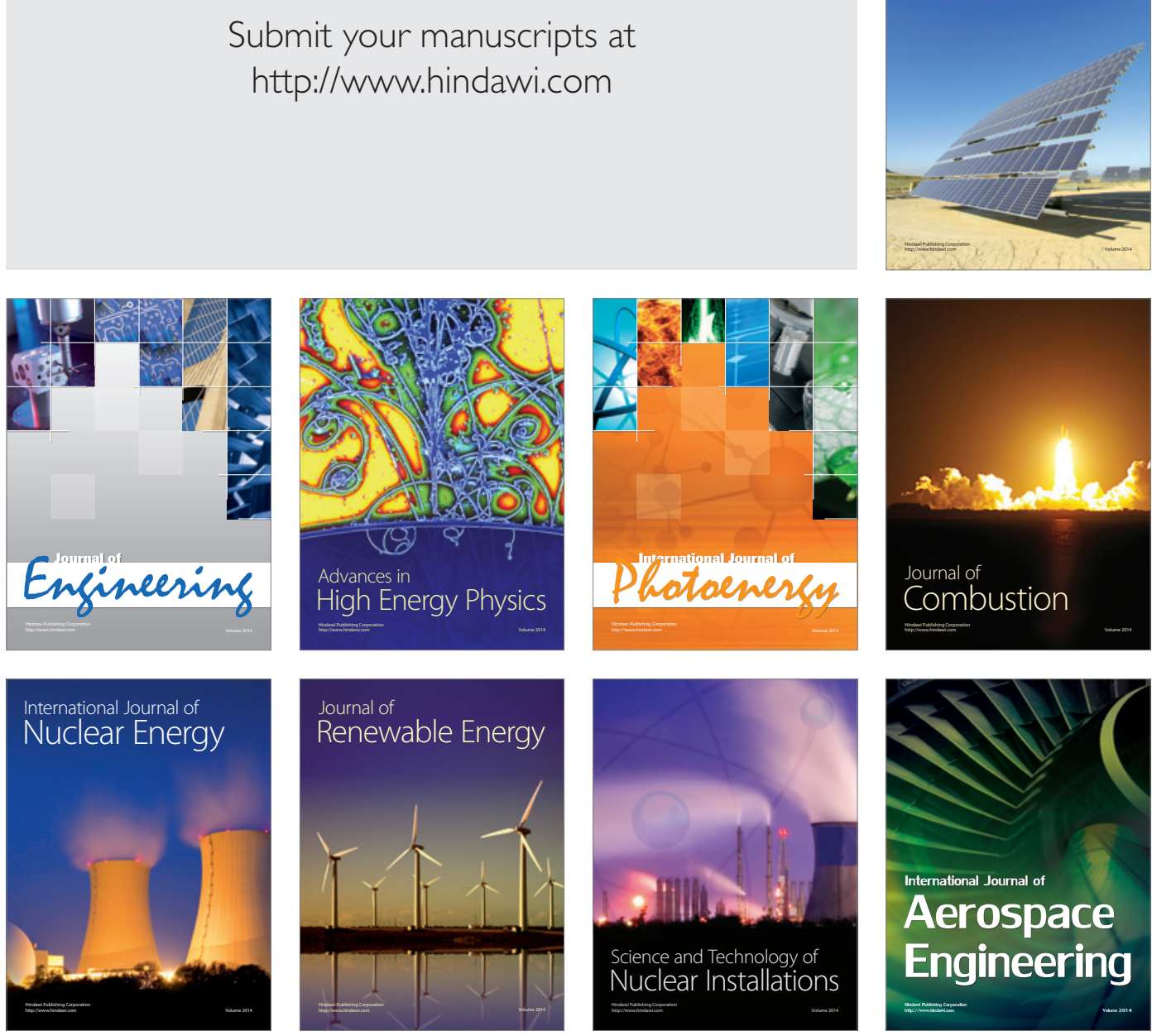